\title{
Socioeconomic Disparities in Osteoporosis Prevalence: Different Results in the Overall Korean Adult Population and Single-person Households
}

\author{
Jungmee Kim ${ }^{1}$, Joongyub Lee², Ju-Young Shin ${ }^{3}$, Byung-Joo Park' \\ ${ }^{1}$ Department of Preventive Medicine, Seoul National University College of Medicine, Seoul; ${ }^{2}$ Medical Research Collaborating Center, Seoul National \\ University Hospital and Seoul National University College of Medicine, Seoul; ${ }^{3}$ Korea Institute of Drug Safety and Risk Management, Seoul, Korea
}

Objectives: The present study was conducted in order to examine the association between socioeconomic status (SES) and osteoporosis prevalence in Korea and to assess whether different associations are found in single-person households.

Methods: A cross-sectional population-based study was conducted using the Korea National Health and Nutrition Examination Survey, from 2008 to 2011. The study subjects were people aged $\geq 50$ years with osteoporosis as defined by bone mineral density. Multivariate logistic models were used to estimate prevalence odds ratios (pORs) and 95\% confidence intervals (Cls). Gender differences in the likelihood of osteoporosis were analyzed based on household income, education level, and residential area.

Results: There were 8221 osteoporosis patients aged $\geq 50$ years, of whom 927 lived in single-person households. There was a gender-specific association between osteoporosis prevalence and all three SES factors that we analyzed: income, education, and residential area. After adjusting for age, SES, and health behaviors, including body mass index (BMI), low household income was only significantly associated with osteoporosis in men, whereas education level had an inverse relationship with osteoporosis only in women ( $p=$ $0.01, p<0.001$, respectively). However, after controlling for age and BMI, rural residency was only associated with osteoporosis in women living in single-person households ( $\mathrm{pOR}, 1.59 ; 95 \% \mathrm{Cl}, 1.05$ to 2.43 ).

Conclusions: The Korean adult population showed a gender-specific relationship between SES and osteoporosis prevalence, with a different pattern found in single-person households.

Key words: Osteoporosis, Socioeconomic status, Single-person household, Education, Income

\section{INTRODUCTION}

The effective management of the health of the elderly is a worldwide issue, both in developed countries and in develop-

Received: November 2, 2014 Accepted: January 12, 2015

Corresponding author: Byung-Joo Park, MD, PhD

103 Daehak-ro, Jongno-gu, Seoul 110-799, Korea

Tel: +82-2-740-8325, Fax: +82-2-740-4830

E-mail: bjpark@snu.ac.kr

This is an Open Access article distributed under the terms of the Creative Commons Attribution Non-Commercial License (http://creativecommons.org/licenses/by$\mathrm{nc} / 3.0 / /$ which permits unrestricted non-commercial use, distribution, and reproduction in any medium, provided the original work is properly cited. ing countries. The burden of osteoporosis, a well-known disease of the elderly, is not trivial in South Korea (hereafter Korea), and one third of Korean women over 50 years of age are at risk of fractures due to impaired bone health [1]. While studies have shown that low socioeconomic status (SES) is associated with a greater need for healthcare [2], health outcomes [3], and health inequities [4], SES has also been reported to affect health behavior and adherence to medication regimens $[5,6]$. Moreover, social inequalities regarding the impact of chronic disease are expected to continue in the future [7].

Several studies have been carried out to assess interventions designed to improve osteoporosis care [8], as well as many 
studies concerning the relationship between SES and osteoporosis medication adherence $[9,10]$. Poverty has been shown to be a definite risk factor for osteoporotic fractures in a study performed in Spain [11], and a study evaluating Canadian women has shown that lower income was found to correlate with a greater likelihood of qualifying for osteoporosis treatment, based on an assessment of the probability of hip fracture [12]. However, a systematic review conducted in 2009 concluded that conflicting evidence exists regarding the relationship between osteoporotic fractures and levels of income and education [13]. Another systematic review published in 2011 identified evidence for a positive association between educational level and bone mineral density (BMD) only in women, but no relationship between income and BMD in either gender [14].

A super-aging society is expected to emerge in this century, meaning that the elderly segment of the population, including single-person households, is expected to rise. Therefore, a comprehensive regional care system for the elderly has been recently adopted in Japan, and such a system has also been discussed in the Netherlands [15]. Since osteoporosis is often neglected prior to a fracture, many individuals, especially those who live alone, will be unaware of their bone health and fracture risk. This is problematic since the one-year mortality of hip fractures in Koreans over 50 years of age is $16.55 \%$, which is 2.85 times higher than that of the same age group in the general population, and is higher in patients with lower SES or who live in places other than the capital city [16]. Moreover, the strongest finding in a previous systemic review of associations between SES and osteoporotic fracture was an increased risk of fracture in the unmarried, single, divorced, or widowed population compared to married couples [13]. Thus, living alone may be assumed to be a risk factor for osteoporotic fracture even though it is not included in the World Health Organization (WHO) risk assessment for fracture.

Although a study has been carried out to assess the influence of living circumstances, including SES, on osteoporosis medication adherence in the elderly [17], and another study has demonstrated the effect of SES on BMD in Korean adults [18], the relationship between SES and osteoporosis prevalence has never been specifically studied in single-person households in Korea. The present study was conducted to determine the association between socioeconomic diversity and the prevalence of osteoporosis in the Korean population of adults older than 50 years and to assess whether different associations are found in singleperson households, controlling for other health behaviors.

\section{METHODS}

\section{Data and Study Subjects}

This study was conducted using data from the Korea National Health and Nutrition Examination Survey (KNHANES), a nationally representative survey composed of health behavior interviews and examinations, including anthropometric measures as well as biochemical and clinical profiles [19]. It is conducted by the Korea Centers for Disease Control and Prevention (KCDC), a part of the Ministry of Health and Welfare. The ethics committee of the KCDC approved KNHANES, which has been conducted discontinuously in 1998, 2001, and 2005, and thereafter annually since 2007 . However, since BMD was only measured from July 2008 to May 2011, this study only included database records from 2008 to 2011. The study subjects were men and women aged $\geq 50$ years with BMD measurements, since osteoporosis was defined using BMD, which is known to decrease beginning at 50 years of age.

The definition of osteopenia or osteoporosis were made using the WHO T-score criteria $(-2.5<\mathrm{T}$-score $<-1$ for osteopenia and Tscore $\leq-2.5$ for osteoporosis), with a reference value of the maximum BMD found in the Japanese population. Areal BMD (g/ $\mathrm{cm}^{2}$ ) was measured with dual-energy X-ray absorptiometry ([DXA], QDR 4500A; Hologic Inc., Waltham, MA, USA) performed by trained technicians. The respondents were classified as having osteoporosis if a sufficiently low T-score was obtained from the femur, femoral neck, or lumbar spine. During the period from 2008 to 2011, a T-score $\leq-3$ was used in Korea as the reimbursement criterion for common osteoporosis medications such as bisphosphonate and raloxifene. This cutoff does not correspond to the WHO cutoff for diagnosing osteoporosis, and therefore data about osteoporosis medication were not used to detect osteoporosis patients in this study. Moreover, osteoporosis patients were not identified by a history of fracture, as this criterion would not distinguish osteoporotic fractures from fractures resulting from other causes. Patients belonging to singleperson households were selected on the basis of a question asking respondents to identify their household type based on a set of options that included "single-person household" along with an extensive range of other configurations.

\section{Measurements and Definitions}

Height was measured to the nearest $0.1 \mathrm{~cm}$ by a stadiometer (Hotan, Crymych, United Kingdom), and weight was measured to the nearest $0.1 \mathrm{~kg}$ by a scale (Giant 150N; Hana Co., Seoul, 
Korea). Income was assessed according to self-reported household income, since each individual reported the income of his or her household. Household income was transformed using the square-root equivalence scale, which divides household income by the square root of the number of the family members. Residential areas were classified as urban or rural according to the population of the administrative district in which each respondent lived. Alcohol consumption was classified as none, moderate (one to two drinks per sitting), and heavy (three or more drinks per sitting), corresponding to the categories defined in the Dietary Guidelines for Americans issued by the Department of Agriculture and the Department of Health and Human Services. Exercise was defined to include activities such as running or jogging, high-speed cycling, fast-paced swimming, soccer, basketball, jump rope, squash, tennis singles, or moving heavy loads that involve an elevated rate of breathing compared to routine daily activities.

\section{Statistical Analysis}

A stratified, multistage, clustered probability sampling method was used in this study. Therefore, sample weights were assigned to participants to represent the non-institutionalized Korean population based on the inverse of selection probabilities and response rates. In order to reflect this sampling method, we used a weighted sample as well as the PROC SURVEYFREQ and PROC SURVEYLOGISTIC procedures in SAS version 9.4 (SAS Institute Inc., Cary, NC, USA). Weights were determined for both health interviews and examinations, since information from those two datasets were used in this study. Since gender interacted with both household income $(p=0.035)$ and educa- tion $(p=0.008)$, gender-specific analyses were carried out for socioeconomic variables. Unweighted frequencies and weighted proportions were estimated. Since it has been demonstrated that many socio-demographic characteristics in the Korean population are related to a lower prevalence of healthy lifestyle behaviors [20], healthy behaviors known to affect bone health were controlled for in the multivariate logistic regression analysis. The factors controlled for included demographic factors such as age and marital status, socioeconomic factors such as household income, education, and residential area, and health behavior factors reflecting known risk factors of osteoporosis, such as smoking, drinking, exercise, and body mass index (BMI). Age was adjusted as a continuous variable; however, since the distribution of age was not entirely linear and the model was affected by including a quadratic term, a quadratic term corresponding to age was also included in the adjustment of the multiple logistic regressions. Subjects with missing variables were excluded from the multivariable analysis. Model fitting was done using the Akaike information criterion and the Schwarz criterion and rechecked using the stepwise variable selection method, which showed that all the variables included in the multivariate logistic regression model were statistically significant. The $p$-values for trends were adopted from the $p$ values of the multivariate logistic regression, considering categorical variables as continuous variables. Adjusted prevalence odds ratios (pOR) and their 95\% confidence intervals were calculated to show the strength of each association. SAS version 9.4 (SAS Institute Inc., Cary, NC, USA) was used for all analyses, and two-sided $p$-values $<0.05$ were considered to indicate statistical significance.

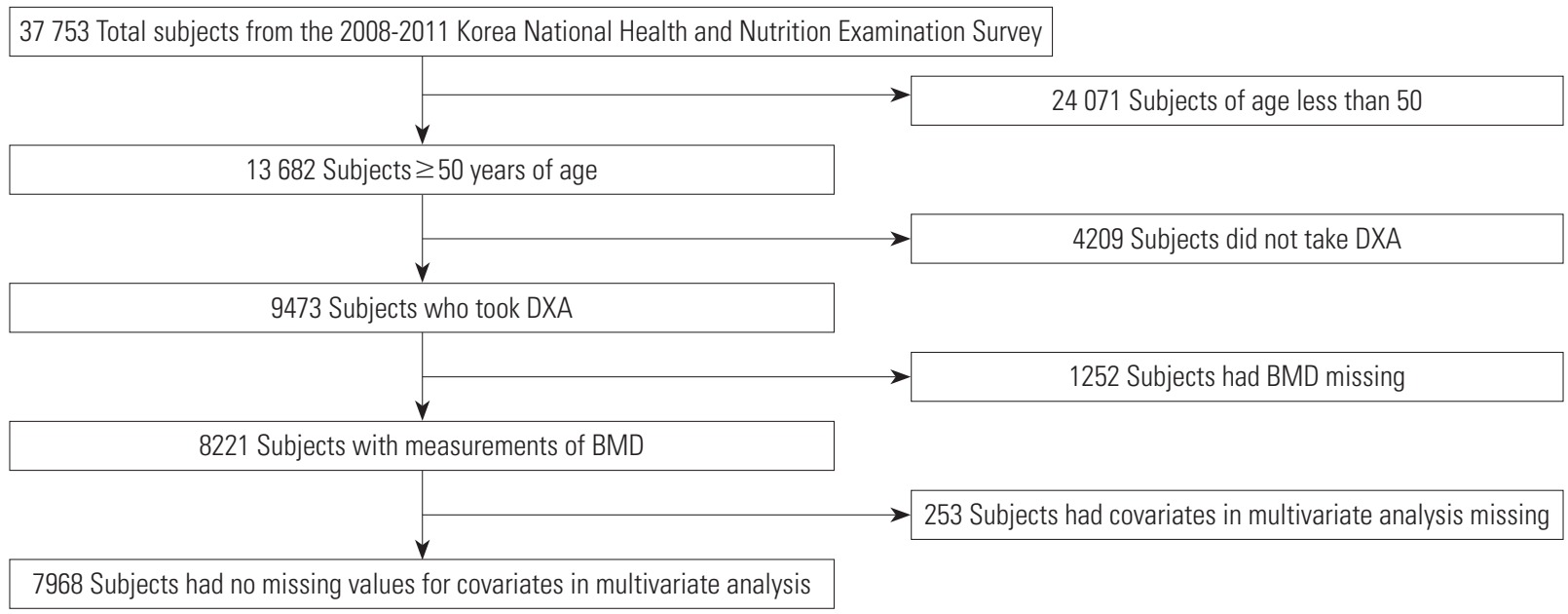

Figure 1. Flow chart of study subject selection. DXA, dualenergy X-ray absorptiometry; BMD, bone mineral density. 


\section{RESULTS}

A flow chart of the study participants is provided in Figure 1. Of the 37753 total participants in KNHANES from 2008 to 2011, 9473 subjects were at least 50 years of age and had taken DXA. Of those, 8221 subjects (86.8\%), who chose to go through the exam according to individual's interest, had BMD measurements. Of these subjects, eleven women were pre-menopausal, 51 women had undergone a bilateral ovary resection, and the remaining women had undergone menopause. A total of 7968 participants with complete records were included in the multivariate analysis. The baseline characteristics of the overall study population are shown in Table 1 and the characteristics of subjects in single-person households are shown in Table 2. Among

Table 1. Baseline characteristics of overall study subjects in unweighted number and weighted percentage from the Korea National Health and Nutrition Examination Survey during 2008 and 2011

\begin{tabular}{|c|c|c|c|}
\hline & $\begin{array}{c}\text { Overall } \\
(n=8221)\end{array}$ & $\begin{array}{c}\text { Men } \\
(\mathrm{n}=3793)\end{array}$ & $\begin{array}{c}\text { Women } \\
(n=4428)\end{array}$ \\
\hline Age (y) & $62.5(0.15)$ & $61.2(0.18)$ & $63.8(0.18)$ \\
\hline $50-59$ & $2880(46.0)$ & $1406(51.3)$ & $1474(40.5)$ \\
\hline $60-69$ & $2925(29.8)$ & $1346(29.2)$ & 1579 (30.3) \\
\hline$\geq 70$ & $2416(24.2)$ & $1041(19.5)$ & $1375(29.3)$ \\
\hline Height (cm) & $160.2(0.13)$ & $167.1(0.12)$ & $153.2(0.12)$ \\
\hline Weight (kg) & $61.7(0.15)$ & $66.5(0.22)$ & $56.8(0.16)$ \\
\hline Body mass index $\left(\mathrm{kg} / \mathrm{m}^{2}\right)$ & $24.0(0.04)$ & $23.8(0.06)$ & $24.2(0.06)$ \\
\hline \multicolumn{4}{|l|}{ Household income } \\
\hline 04 (highest) & $1603(22.4)$ & $849(26.4)$ & $754(18.3)$ \\
\hline 03 & $1614(21.1)$ & $806(22.3)$ & $808(20.0)$ \\
\hline 02 & $2094(25.3)$ & $980(25.4)$ & $1114(25.3)$ \\
\hline 01 (lowest) & $2785(29.3)$ & $1103(24.3)$ & $1682(34.3)$ \\
\hline Missing or unknown & $125(1.9)$ & $55(1.6)$ & $70(2.1)$ \\
\hline \multicolumn{4}{|l|}{ Residential area } \\
\hline Urban & $5487(71.3)$ & $2539(71.8)$ & $2948(70.9)$ \\
\hline Rural & $2734(28.7)$ & $1254(28.2)$ & $1480(29.1)$ \\
\hline \multicolumn{4}{|l|}{ Marital status } \\
\hline Married & $6282(77.6)$ & $3467(91.2)$ & $2815(63.9)$ \\
\hline Separated or widowed & $1916(22.1)$ & $315(8.5)$ & $1601(35.8)$ \\
\hline Missing or unknown & $23(0.3)$ & $11(0.3)$ & $12(0.2)$ \\
\hline \multicolumn{4}{|l|}{ Education } \\
\hline College or higher & $843(11.5)$ & $647(18.3)$ & $196(4.7)$ \\
\hline Middle/high school & 2979 (39.7) & $1760(48.6)$ & $1219(30.7)$ \\
\hline Primary school & $4312(47.7)$ & $1349(32.1)$ & $2963(63.3)$ \\
\hline Missing or unknown & $87(1.1)$ & $37(1.0)$ & $50(1.2)$ \\
\hline
\end{tabular}

the 8221 total subjects, $3793(46.1 \%)$ were men and 4428 (53.0\%) were women, while among the 927 single-person household subjects, 196 (21.1\%) were men and 731 (78.9\%) were women. In the overall study population, women were more prevalent in the categories of elderly subjects, those with a low household income, and those with a low level of education. Moreover, while most of the men were married and cohabitating with their spouses, a higher proportion of women were living alone after being separated or widowed. However, men were more prevalent in the categories of current smokers and heavy drinkers. More women than men had a poor BMD status, and about nine percent of women were being treated with medication for osteoporosis. Single-person households had a higher proportion of respondents who reported the low-

Table 1. Continued

\begin{tabular}{|c|c|c|c|}
\hline & $\begin{array}{c}\text { Overall } \\
(\mathrm{n}=8221)\end{array}$ & $\begin{array}{c}\text { Men } \\
(n=3793)\end{array}$ & $\begin{array}{l}\text { Women } \\
(n=4428)\end{array}$ \\
\hline \multicolumn{4}{|l|}{ Smoking } \\
\hline Never smoker & 4635 (52.6) & $616(15.5)$ & 4019 (89.8) \\
\hline Former smoker & $956(12.5)$ & $890(23.2)$ & $66(1.7)$ \\
\hline Current smoker & $2563(34.0)$ & $2260(60.5)$ & $303(7.3)$ \\
\hline Missing or unknown & $67(1.0)$ & $27(0.8)$ & $40(1.1)$ \\
\hline \multicolumn{4}{|l|}{ Drinking $^{1}$} \\
\hline None & $3397(37.6)$ & $940(22.2)$ & $2457(53.1)$ \\
\hline Moderate & $2112(24.4)$ & $738(17.3)$ & $1374(31.6)$ \\
\hline Heavy & $2644(37.0)$ & $2088(59.6)$ & 556 (14.2) \\
\hline Missing or unknown & $68(1.0)$ & $27(0.9)$ & $41(1.1)$ \\
\hline \multicolumn{4}{|l|}{ Exercise $^{2}$ (d/wk) } \\
\hline$\geq 3$ & $1159(15.2)$ & $652(18.6)$ & $507(11.9)$ \\
\hline$\leq 2$ & $830(11.4)$ & $503(15.2)$ & $327(7.6)$ \\
\hline None & $6148(72.2)$ & $2604(65.1)$ & $3544(79.2)$ \\
\hline Missing or unknown & $84(1.2)$ & $34(1.1)$ & $50(1.4)$ \\
\hline \multicolumn{4}{|c|}{ Bone mineral density status } \\
\hline Normal & $2181(29.7)$ & $1627(45.6)$ & $554(13.8)$ \\
\hline Osteopenia & $3973(47.9)$ & 1838 (46.9) & 2135 (48.9) \\
\hline Osteoporosis & 2067 (22.4) & $328(7.5)$ & 1739 (37.3) \\
\hline \multicolumn{4}{|l|}{ Osteoporosis treatment } \\
\hline Yes & $165(8.0)$ & $6(1.8)$ & $159(9.1)$ \\
\hline \multicolumn{4}{|c|}{ Hormone replacement therapy } \\
\hline Yes & - & - & $339(7.5)$ \\
\hline No & - & - & $1648(40.5)$ \\
\hline Missing or unknown & - & - & $2441(52.0)$ \\
\hline \multicolumn{4}{|c|}{$\begin{array}{l}\text { Values are presented as mean (standard error) or number (\%). } \\
{ }^{1} \text { Moderate: } 1-2 \text { drinks/sitting, heavy: over } 3 \text { drinks/sitting. } \\
\text { 2Physical activities such as work-related or sports activities including run } \\
\text { ning or jogging, high-speed cycling, fast-paced swimming, soccer, basket } \\
\text { ball, jump rope, squash racquets, tennis singles, or moving heavy loads tha } \\
\text { involves the individuals under the pressure of fast-paced breathing thar } \\
\text { usual daily activities. }\end{array}$} \\
\hline
\end{tabular}


est quartile of household income, who lived in rural areas, who were separated or widowed, who had a low level of education, who were sedentary, and who had osteoporosis. This effect was mainly due to the over-representation of women in this category.

The pORs for osteoporosis prevalence in all subjects and in single-person household participants are shown in Table 3, and gender-specific pOR scores corresponding to different socioeconomic factors are shown in Table 4. Logistic regression showed a significant positive association between marital status and osteoporosis prevalence in the overall population but not in single-person households, whereas a significant positive association between residential area and osteoporosis preva-

Table 2. Baseline characteristics of single-person household subjects in unweighted number and weighted percentage from the Korea National Health and Nutrition Examination Survey during 2008 and 2011

\begin{tabular}{|c|c|c|c|}
\hline & $\begin{array}{l}\text { Overall } \\
(\mathrm{n}=927)\end{array}$ & $\begin{array}{c}\text { Men } \\
(n=196)\end{array}$ & $\begin{array}{l}\text { Women } \\
(n=731)\end{array}$ \\
\hline Age (y) & $68.3(0.4)$ & $63.6(1.0)$ & $69.9(0.4)$ \\
\hline $50-59$ & $136(22.7)$ & $52(43.9)$ & $84(15.3)$ \\
\hline $60-69$ & 306 (27.5) & $65(25.5)$ & $241(28.2)$ \\
\hline$\geq 70$ & $485(49.9)$ & 79 (30.6) & $406(56.5)$ \\
\hline Height (cm) & $155.2(0.4)$ & $166.0(0.5)$ & $151.4(0.2)$ \\
\hline Weight (kg) & $57.9(0.4)$ & $64.5(0.9)$ & $55.7(0.4)$ \\
\hline Body mass index $\left(\mathrm{kg} / \mathrm{m}^{2}\right)$ & $24.0(0.1)$ & $23.3(0.3)$ & $24.2(0.1)$ \\
\hline \multicolumn{4}{|l|}{ Household income } \\
\hline Q4 (highest) & $45(6.6)$ & $23(16.1)$ & $22(3.3)$ \\
\hline 03 & $49(6.6)$ & $18(11.7)$ & $31(4.9)$ \\
\hline 02 & $162(18.2)$ & $41(23.5)$ & $121(16.4)$ \\
\hline 01 (lowest) & $665(68.0)$ & $110(47.2)$ & $555(75.2)$ \\
\hline Missing or unknown & $6(0.5)$ & $4(1.6)$ & $2(0.2)$ \\
\hline \multicolumn{4}{|l|}{ Residential area } \\
\hline Urban & 544 (61.4) & $117(64.8)$ & $427(60.2)$ \\
\hline Rural & $383(38.6)$ & 79 (35.2) & 304 (39.8) \\
\hline \multicolumn{4}{|l|}{ Marital status } \\
\hline Married & $62(7.8)$ & $40(19.6)$ & $22(3.8)$ \\
\hline Separated or widowed & $865(92.1)$ & $156(80.4)$ & $709(96.2)$ \\
\hline \multicolumn{4}{|l|}{ Education } \\
\hline College or higher & $40(5.4)$ & $22(13.1)$ & $18(2.7)$ \\
\hline Middle/high school & $174(22.6)$ & $84(46.0)$ & $90(14.6)$ \\
\hline Primary school & $704(71.1)$ & $89(40.6)$ & $615(81.7)$ \\
\hline Missing or unknown & $9(0.8)$ & $1(0.3)$ & $8(1.1)$ \\
\hline
\end{tabular}

lence was only found in single-person households. However, while the above-mentioned associations of income and education with osteoporosis were significant in the overall sample, a gender-specific analysis showed that education was only a significant factor among women and income was only a significant factor among men. Moreover, after adjusting for age and BMI, living in rural areas significantly increased osteoporosis prevalence only among women in single-person households.

\section{DISCUSSION}

The objective of the present study was to determine the association between socioeconomic factors and osteoporosis preva-

Table 2. Continued

\begin{tabular}{|c|c|c|c|}
\hline & $\begin{array}{c}\text { Overall } \\
(\mathrm{n}=927)\end{array}$ & $\begin{array}{c}\text { Men } \\
(n=196)\end{array}$ & $\begin{array}{l}\text { Women } \\
(n=731)\end{array}$ \\
\hline \multicolumn{4}{|l|}{ Smoking } \\
\hline Never smoker & $648(64.9)$ & $27(12.0)$ & $621(83.1)$ \\
\hline Former smoker & $57(7.8)$ & $42(23.9)$ & $15(2.2)$ \\
\hline Current smoker & $215(26.4)$ & $126(63.5)$ & $89(13.6)$ \\
\hline Missing or unknown & $7(0.9)$ & $1(0.5)$ & $6(1.0)$ \\
\hline \multicolumn{4}{|l|}{ Drinking ${ }^{1}$} \\
\hline None & $513(52.7)$ & $56(25.7)$ & $457(62.0)$ \\
\hline Moderate & $222(22.6)$ & $42(18.8)$ & $180(23.9)$ \\
\hline Heavy & $184(23.8)$ & $98(55.5)$ & $86(12.9)$ \\
\hline Missing or unknown & $8(0.9)$ & $0(0.0)$ & $8(1.2)$ \\
\hline \multicolumn{4}{|l|}{ Exercise $^{2}$ (d/wk) } \\
\hline$\geq 3$ & $100(10.5)$ & $30(15.3)$ & $70(8.8)$ \\
\hline$\leq 2$ & $70(9.8)$ & $22(16.7)$ & $48(7.3)$ \\
\hline None & $747(78.2)$ & $142(66.2)$ & $605(82.4)$ \\
\hline Missing or unknown & $10(1.5)$ & $2(1.8)$ & $8(1.5)$ \\
\hline \multicolumn{4}{|c|}{ Bone mineral density status } \\
\hline Normal & $107(13.4)$ & $68(36.4)$ & $39(5.5)$ \\
\hline Osteopenia & $411(45.3)$ & 101 (52.3) & $310(42.9)$ \\
\hline Osteoporosis & $409(41.3)$ & $27(11.3)$ & $382(51.7)$ \\
\hline \multicolumn{4}{|l|}{ Osteoporosis treatment } \\
\hline Yes & $28(6.8)$ & $0(0.0)$ & $28(7.3)$ \\
\hline \multicolumn{4}{|c|}{ Hormone replacement therapy } \\
\hline Yes & & & $27(4.0)$ \\
\hline No & & & $245(39.9)$ \\
\hline Missing or unknown & & & $459(56.0)$ \\
\hline \multicolumn{4}{|c|}{$\begin{array}{l}\text { Values are presented as mean (standard error) or number (\%). } \\
{ }^{1} \text { Moderate: } 1-2 \text { drinks/sitting, heavy: over } 3 \text { drinks/sitting. } \\
{ }^{2} \text { Physical activities such as work-related or sports activities including run } \\
\text { ning or jogging, high-speed cycling, fast-paced swimming, soccer, basket } \\
\text { ball, jump rope, squash racquets, tennis singles, or moving heavy loads tha } \\
\text { involves the individuals under the pressure of fast-paced breathing thar } \\
\text { usual daily activities. }\end{array}$} \\
\hline
\end{tabular}


lence in the national population overall and in single-person households in particular. The different gender distribution of study subjects across the demographic variables included in the present study corresponds closely to the results of earlier studies investigating the prevalence and risk factors of osteoporosis, such as a Korean prospective cohort study [21] and a study based on the Korean Community Health Survey [20]. Women tended to comprise the more vulnerable population with regard to income, education, and exercise status, while men were over-represented in groups showing unhealthy smoking and drinking behavior. The positive effect of married couples in reducing osteoporosis prevalence was significant in the adult population. This corresponds with many other studies of associ-

Table 3. Prevalence odds ratios for osteoporosis in overall and single-person household study subjects from the Korean National Health and Nutrition Examination Survey during 2008 and 2011

\begin{tabular}{|c|c|c|c|c|}
\hline & $\mathbf{n}$ & $\begin{array}{c}\text { Overall1 }^{1} \\
(\mathrm{n}=7968)\end{array}$ & $\mathbf{n}$ & $\begin{array}{l}\text { Single-person } \\
\text { household }^{1} \\
(n=902)\end{array}$ \\
\hline \multicolumn{5}{|l|}{ Age } \\
\hline $50-59$ & 2821 & 1.00 & 133 & 1.00 \\
\hline $60-69$ & 2835 & $3.07(2.54,3.72)$ & 300 & $5.58(3.00,10.37)$ \\
\hline$\geq 70$ & 2312 & $9.63(7.97,11.64)$ & 469 & $14.94(7.94,28.10)$ \\
\hline$p$ for trend & & $<0.001$ & & $<0.001$ \\
\hline \multicolumn{5}{|l|}{ Household income } \\
\hline 04 (highest) & 1592 & 1.00 & 44 & 1.00 \\
\hline 03 & 1598 & $1.21(0.93,1.56)$ & 49 & $1.49(0.40,5.61)$ \\
\hline 02 & 2057 & $1.25(1.00,1.56)$ & 160 & $2.00(0.67,6.00)$ \\
\hline 01 (lowest) & 2726 & $1.52(1.24,1.87)$ & 649 & $2.67(0.40,5.61)$ \\
\hline$p$ for trend & & $<0.001$ & & 0.02 \\
\hline \multicolumn{5}{|l|}{ Residential area } \\
\hline Urban & 5296 & 1.00 & 527 & 1.00 \\
\hline Rural & 2672 & $1.06(0.91,1.24)$ & 375 & $1.63(1.19,2.20)$ \\
\hline$p$-value & & 0.47 & & 0.002 \\
\hline \multicolumn{5}{|l|}{ Marital status } \\
\hline Married & 6141 & 1.00 & 61 & 1.00 \\
\hline Separated or widowed & 1827 & $2.45(2.12,2.84)$ & 841 & $2.14(0.93,4.91)$ \\
\hline$p$-value & & $<0.001$ & & 0.07 \\
\hline \multicolumn{5}{|l|}{ Education } \\
\hline College or higher & 829 & 1.00 & 39 & 1.00 \\
\hline Middle-high school & 2924 & $1.80(1.30,2.50)$ & 171 & $1.33(0.34,5.22)$ \\
\hline Primary school & 4215 & $4.16(3.06,5.65)$ & 692 & $3.97(1.03,15.26)$ \\
\hline$p$ for trend & & $<0.001$ & & $<0.001$ \\
\hline
\end{tabular}

(Continued to the next) ations between fracture risk and marital status [13], and can be explained by the social support provided by marriage, which may influence health behaviors and inculcate a greater awareness of the other partner [22].

However, household income was only significantly associated with osteoporosis prevalence in men. This is in close agreement with the relationship between SES and obesity [23], but is distinct from dyslipidemia, which exhibits an association with low income only in women [24], and diabetes, which is not associated with income level in either gender [25]. In the case of income level and osteoporosis, the results of the present study differ from previous studies reporting that women with lower incomes had a higher risk of osteoporosis, resulting from their

Table 3. Continued

\begin{tabular}{|c|c|c|c|c|}
\hline & n & $\begin{array}{c}\text { Overall }^{1} \\
(\mathrm{n}=7968)\end{array}$ & n & $\begin{array}{l}\text { Single-person } \\
\text { household }^{1} \\
(n=902)\end{array}$ \\
\hline \multicolumn{5}{|l|}{ Smoking } \\
\hline Never smoker & 4522 & 1.00 & 636 & 1.00 \\
\hline Former smoker & 941 & $0.19(0.14,0.26)$ & 57 & $0.30(0.14,0.64)$ \\
\hline Current smoker & 2505 & $0.27(0.23,0.33)$ & 209 & $0.63(0.41,0.97)$ \\
\hline$p$ for trend & & $<0.001$ & & 0.01 \\
\hline \multicolumn{5}{|l|}{ Drinking $^{2}$} \\
\hline None & 3305 & 1.00 & 502 & 1.00 \\
\hline Moderate & 2065 & $0.74(0.62,0.88)$ & 219 & $0.85(0.55,1.32)$ \\
\hline Heavy & 2598 & $0.29(0.23,0.35)$ & 181 & $0.45(0.27,0.75)$ \\
\hline$p$ for trend & & $<0.001$ & & 0.004 \\
\hline \multicolumn{5}{|l|}{ Exercise $^{3}$ (d/wk) } \\
\hline$\geq 3$ & 1143 & 1.00 & 99 & 1.00 \\
\hline$\leq 2$ & 817 & $0.94(0.69,1.28)$ & 70 & $1.17(0.51,2.66)$ \\
\hline None & 6008 & $1.42(1.14,1.77)$ & 733 & $1.05(0.59,1.86)$ \\
\hline$p$ for trend & & $<0.001$ & & 0.96 \\
\hline \multicolumn{5}{|l|}{ Body mass index ${ }^{4}$} \\
\hline Underweight & 263 & $2.23(1.50,3.31)$ & 37 & $2.63(0.79,8.73)$ \\
\hline Normal weight & 2834 & 1.00 & 317 & 1.00 \\
\hline Overweight & 2101 & $0.67(0.56,0.79)$ & 195 & $0.66(0.43,1.02)$ \\
\hline Obese & 2770 & $0.53(0.45,0.62)$ & 353 & $0.50(0.35,0.73)$ \\
\hline$p$ for trend & & $<0.001$ & & $<0.001$ \\
\hline
\end{tabular}

Values are presented as odds ratio ( $95 \%$ confidence interval).

${ }^{1}$ Adjusted for age as a continuous variable with quadric term included.

${ }^{2}$ Moderate: 1-2 drinks/sitting, heavy: over 3 drinks/sitting.

${ }^{3}$ Physical activities such as work-related or sports activities including running or jogging, high-speed cycling, fast-paced swimming, soccer, basketball, jump rope, squash racquets, tennis singles, or moving heavy loads that involves the individuals under the pressure of fast-paced breathing than usual daily activities.

${ }^{4}$ According to the Asian criterion of body mass index, underweight $(<18.5$ $\left.\mathrm{kg} / \mathrm{m}^{2}\right)$, normal weight $\left(18.5-22.9 \mathrm{~kg} / \mathrm{m}^{2}\right)$, overweight $\left(23.0-24.9 \mathrm{~kg} / \mathrm{m}^{2}\right)$, and obese $\left(\geq 25.0 \mathrm{~kg} / \mathrm{m}^{2}\right)$. 
Table 4. Prevalence odds ratios for osteoporosis in overall and single-person household study subjects according to income levels, education status, and residential area from the Korea National Health and Nutrition Examination Survey during 2008 and 2011

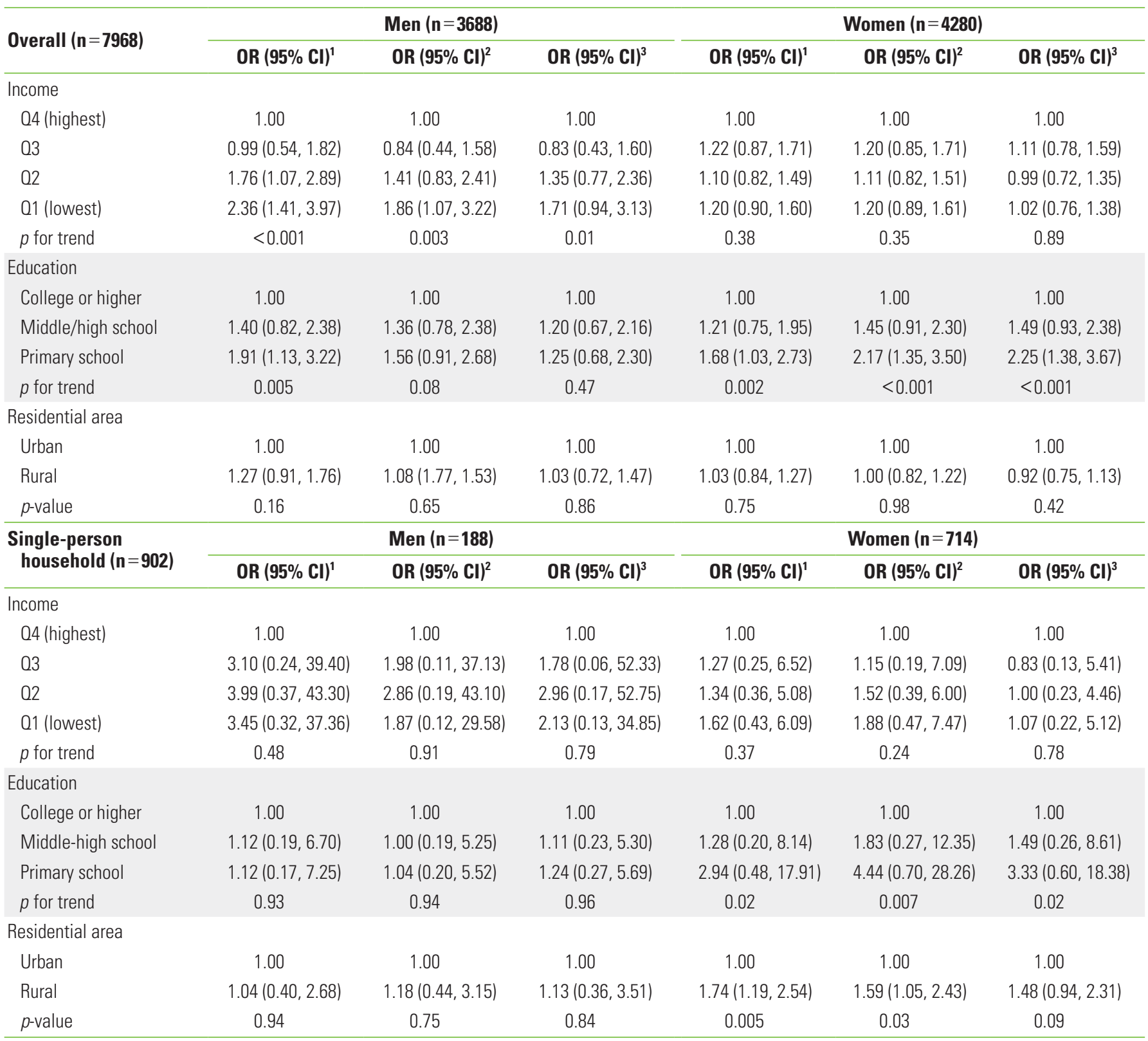

${ }^{1}$ Adjusted for age as a continuous variable with quadric term included.

${ }^{2}$ Adjusted for age as a continuous variable with quadric term included and body mass index as a continuous variable.

${ }^{3}$ Adjusted for age, body mass index, marital status, household income, education, residential area, smoking, drinking, and exercise.

older age and lower height, which indicated poor nutrition [11]. However, a pattern in which people with lower incomes were older and shorter also occurred among the men in our study subjects. The relationship between income and osteoporosis risk in men is a subject of controversy. Although some studies have shown a positive relationship between income and BMD in men $[18,26]$, one study in New Zealand has reported an inverse relationship [27], and other studies have found no rela- tionship [28,29]. Two studies carried out in Korea also found different patterns. One study was based on a rural area with an age group ranging from 40 to 79 years and showed no relationship between income and BMD among men [21], while another study, drawing on an age group from 19 to 95 years, showed a positive relationship between income and BMD among men [18]. It has been suggested that the relationship between SES and BMD varies according to age [30]. The present 
study uniquely assesses the national adult population aged 50 years or older and thereby fully presents the remarkably different gender-specific patterns found in the association between SES and osteoporosis. In addition, among the referenced studies above, the study from New Zealand uniquely categorized SES by using occupations as a proxy for education and income, while the rest studies evaluated monthly income at the time of interview. Also, in the former study, majority of low SES population were involved in manual labor which could enhance bone health. This could be one reason for the different results.

Although a correlation between education and osteoporosis was only found among women in one previous study [14], such an association was found in both genders in a Korean cohort study and another KNHANES study [21,31]. However, education was only significantly associated with osteoporosis in women in the present study. Similarly, various disparities in the relationship of income and education with diabetes were seen in a previous study using the KNHANES database [32]. However, in that study, various health care processes and the health outcomes of diabetes were analyzed separately, and education was ultimately shown to be associated with both categories, whereas income was only associated with health outcomes. Some of the reasons suggested for this discrepancy were the lowered financial barriers to physician visits due to the Korean national health insurance system and the suboptimal health behaviors of the poor, which lead to worse health outcomes. However, the present study was not able to incorporate the presence of a BMD test, which is a typical health care process involved in osteoporosis management, as a dependent variable, since the disease status of the study population was defined through BMD. Moreover, among unhealthy behaviors, lower income was not associated with smoking, but was associated with alcohol consumption in this study population (Mantel-Haenszelchi-squared $p=0.724$, $p<0.0001$, respectively). Therefore, planned interventions targeting osteoporosis management should take into account the social background of gender disparities with regard to the relationship of income and education with osteoporosis prevalence.

Moreover, the causality between education and health behaviors is an area in which various hypotheses and explanations have been proposed. Koreans with good self-perceived health status are known to be less likely to be aware of their osteoporosis status and less likely to receive treatment [31]. However, in this study population, unhealthy behavior regarding smoking and alcohol consumption was unexpectedly correlated with lower osteoporosis prevalence, and current smokers and heavy drinkers were found to have better self-perceived health status and higher education levels (Mantel-Haenszelchi-squared $p<0.0001$ in both cases) than people with healthy behaviors. In light of these findings, it might be more important to develop strategies for translating intentions into actions that are motivated by one's awareness of the disease, rather than focusing on specific health knowledge, discount rate, or value of the future, because all of those traits are known to correlate with education [33]. Therefore, health promotion programs for chronic diseases, especially silent diseases with low treatment rates, such as osteoporosis, must be planned to motivate people according to their knowledge level.

Living in rural areas was only significantly associated with osteoporosis in women belonging to single-person households. In a Korean study of low-income women, women in urban areas were more likely to have low physical activity, higher levels of smoking, alcohol consumption, and higher fracture rates [34]. However, the rural residents of single-person households in our data had higher proportions of current smoking, abstinence from alcohol consumption, and lack of exercise. Since drinking was inversely associated with osteoporosis prevalence among single-person households, the population-wide distribution of health behaviors may be one explanation for the significantly higher osteoporosis risk found in rural areas. In addition, it is possible that this population can exhibit a lack of exercise due to either the presence of severe comorbidities or a lack of environmental support for exercise, and it is also likely that some members of this population perform significant physical work that was not counted as exercise. The reason that this association was not significant in men may be explained by the small number of men belonging to single-person households living in rural areas. It has also been reported that osteoporosis medication adherence is lower in rural areas [17]. In light of the above findings, rural residents, those especially living alone, need additional attention in osteoporosis management.

The major strength of this study is the representative sample provided by the KNHANES database, which is a nationwide survey performed by trained staffs who have completed training courses. The "KCDC" and related academic societies have managed external quality control regarding survey administration, data collection, laboratory analysis, and data processing in addition to internal quality control processes. Also, this study is unique in that it also focuses on the health problems of singleperson households, who are at risk of many silent diseases. However, the present study also has some limitations. One limi- 
tation is the cross-sectional nature of the study design, which limits the ability to draw causal inferences and assess timevarying effects based on its results, since childhood SES can also influence BMD [35]. Second, the measurement of income used is different from that used in some other studies. It is known that when household income is used directly, the relative poverty rate is exaggerated. In this study, monthly household income was transformed using the square-root equivalence scale, which divides household income by the square root of the family size. However, the consumption level of a family can vary according to the age group of the family members, which represents a possible complication that was not considered in the equivalence scale used in this study. Moreover, the number of one-member families has increased recently in Korea, which makes it difficult to apply the equivalence scale. Third, other risk factors for osteoporosis, such as dietary factors or reproductive history, were not considered. However, these factors have reported to have a relatively small impact on osteoporosis overall [36], and it was not necessary to consider menopausal status, although it is a potentially important factor, because the vast majority of the women included in this study were either menopausal or had undergone bilateral ovary resection.

In conclusion, while osteoporosis was more likely among women with a lower level of education, it was more prevalent among men with a lower household income after adjusting for SES and health behaviors. However, rural residency was a risk factor for osteoporosis in women belonging to single-person households after adjusting for age and BMI. Optimal health service plans for each vulnerable population group are required in order to maximize the effect of interventions designed to improve bone health and eventually prevent fractures. As well, the rural or urban character of residential areas should be taken into account when planning osteoporosis management for individuals belonging to single-person households.

\section{CONFLICT OF INTEREST}

The authors have no conflicts of interest with the material presented in this paper.

\section{REFERENCES}

1. Choi HJ, Shin CS, Ha YC, Jang S, Jang S, Park C, et al. Burden of osteoporosis in adults in Korea: a national health insurance database study. J Bone Miner Metab 2012;30(1):54-58.

2. Shin $\mathrm{H}$, Kim J. Differences in income-related inequality and horizontal inequity in ambulatory care use between rural and nonrural areas: using the 1998-2001 U.S. National Health Interview Survey data. Int J Equity Health 2010;9:17.

3. Ahnquist J, Wamala SP, Lindstrom M. Social determinants of health--a question of social or economic capital? Interaction effects of socioeconomic factors on health outcomes. Soc Sci Med 2012;74(6):930-939.

4. Kim E, Kwon S, Xu K. Has income-related inequity in health care utilization and expenditures been improved? Evidence from the Korean National Health and Nutrition Examination Survey of 2005 and 2010. J Prev Med Public Health 2013;46(5):237-248.

5. Campbell DJ, Ronksley PE, Manns BJ, Tonelli M, Sanmartin C, Weaver RG, et al. The association of income with health behavior change and disease monitoring among patients with chronic disease. PLoS One 2014;9(4):e94007.

6. Rolnick SJ, Pawloski PA, Hedblom BD, Asche SE, Bruzek RJ. Patient characteristics associated with medication adherence. Clin Med Res 2013;11(2):54-65.

7. Galobardes B, Costanza MC, Bernstein MS, Delhumeau C, Morabia A. Trends in risk factors for lifestyle-related diseases by socioeconomic position in Geneva, Switzerland, 1993-2000: health inequalities persist. Am J Public Health 2003;93(8):1302-1309.

8. Hiligsmann M, Salas M, Hughes DA, Manias E, Gwadry-Sridhar FH, Linck P, et al. Interventions to improve osteoporosis medication adherence and persistence: a systematic review and literature appraisal by the ISPOR Medication Adherence \& Persistence Special Interest Group. Osteoporos Int 2013;24(12): 2907-2918.

9. Devold HM, Furu K, Skurtveit S, Tverdal A, Falch JA, Sogaard AJ. Influence of socioeconomic factors on the adherence of alendronate treatment in incident users in Norway. Pharmacoepidemiol Drug Saf 2012;21(3):297-304.

10. Shehadeh-Sheeny A, Eilat-Tsanani S, Bishara E, Baron-Epel 0. Knowledge and health literacy are not associated with osteoporotic medication adherence, however income is, in Arab postmenopausal women. Patient Educ Couns 2013;93(2):282-288.

11. Navarro MC, Sosa M, Saavedra P, Lainez P, Marrero M, Torres M, et al. Poverty is a risk factor for osteoporotic fractures. Osteoporos Int 2009;20(3):393-398.

12. Brennan SL, Leslie WD, Lix LM. Is lower income associated with an increased likelihood of qualification for treatment for osteoporosis in Canadian women? Osteoporos Int 2014;25(1):273-279. 13. Brennan SL, Pasco JA, Urquhart DM, Oldenburg B, Hanna F, 
Wluka AE. The association between socioeconomic status and osteoporotic fracture in population-based adults: a systematic review. Osteoporos Int 2009;20(9):1487-1497.

14. Brennan SL, Pasco JA, Urquhart DM, Oldenburg B, Wang Y, Wluka AE. Association between socioeconomic status and bone mineral density in adults: a systematic review. Osteoporos Int 2011;22(2):517-527.

15. Plochg T, Klazinga NS. Community-based integrated care: myth or must? Int J Qual Health Care 2002;14(2):91-101.

16. Kang HY, Yang KH, Kim YN, Moon SH, Choi WJ, Kang DR, et al. Incidence and mortality of hip fracture among the elderly population in South Korea: a population-based study using the national health insurance claims data. BMC Public Health 2010; 10:230.

17. Doggrell SA, Kairuz T. Comparative studies of how living circumstances influence medication adherence in $\geq 65$ year olds. Int J Clin Pharm 2014;36(1):30-35.

18. Myong JP, Kim HR, Choi SE, Koo JW. The effect of socioeconomic position on bone health among Koreans by gender and menopausal status. Calcif Tissue Int 2012;90(6):488-495.

19. Kweon S, Kim Y, Jang MJ, Kim Y, Kim K, Choi S, et al. Data resource profile: the Korea National Health and Nutrition Examination Survey (KNHANES). Int J Epidemiol 2014;43(1):69-77.

20. Ryu SY, Park J, Choi SW, Han MA. Associations between sociodemographic characteristics and healthy lifestyles in Korean adults: the result of the 2010 Community Health Survey. J Prev Med Public Health 2014;47(2):113-123.

21. Shin CS, Choi HJ, Kim MJ, Kim JT, Yu SH, Koo BK, et al. Prevalence and risk factors of osteoporosis in Korea: a communitybased cohort study with lumbar spine and hip bone mineral density. Bone 2010;47(2):378-387.

22. Guilley E, Herrmann F, Rapin CH, Hoffmeyer P, Rizzoli R, Chevalley T. Socioeconomic and living conditions are determinants of hip fracture incidence and age occurrence among communitydwelling elderly. Osteoporos Int 2011;22(2):647-653.

23. Kim J, Sharma SV, Park SK. Association between socioeconomic status and obesity in adults: evidence from the 2001 to 2009 Korea national health and nutrition examination survey. J Prev Med Public Health 2014;47(2):94-103.

24. Nam GE, Cho KH, Park YG, Han KD, Choi YS, Kim SM, et al. Socioeconomic status and dyslipidemia in Korean adults: the 2008-2010 Korea National Health and Nutrition Examination Survey. Prev Med 2013;57(4):304-309.
25. Lee DS, Kim YJ, Han HR. Sex differences in the association between socio-economic status and type 2 diabetes: data from the 2005 Korean National Health and Nutritional Examination Survey (KNHANES). Public Health 2013;127(6):554-560.

26. Araujo AB, Yang M, Suarez EA, Dagincourt N, Abraham JR, Chiu $\mathrm{G}$, et al. Racial/ethnic and socioeconomic differences in bone loss among men. J Bone Miner Res 2014;29(12):2552-2560.

27. Elliot JR, Gilchrist NL, Wells JE. The effect of socioeconomic status on bone density in a male Caucasian population. Bone 1996;18(4):371-373.

28. Nabipour I, Cumming R, Handelsman DJ, Litchfield M, Naganathan V, Waite $L$, et al. Socioeconomic status and bone health in community-dwelling older men: the CHAMP Study. Osteoporos Int 2011;22(5):1343-1353.

29. Syddall HE, Evandrou M, Dennison EM, Cooper C, Sayer AA. Social inequalities in osteoporosis and fracture among community-dwelling older men and women: findings from the Hertfordshire Cohort Study. Arch Osteoporos 2012;7(1-2):37-48.

30. Brennan SL, Henry MJ, Wluka AE, Nicholson GC, Kotowicz MA, Pasco JA. Socioeconomic status and bone mineral density in a population-based sample of men. Bone 2010;46(4):993-999.

31. Kim KH, Lee K, Ko YJ, Kim SJ, Oh SI, Durrance DY, et al. Prevalence, awareness, and treatment of osteoporosis among Korean women: The Fourth Korea National Health and Nutrition Examination Survey. Bone 2012;50(5):1039-1047.

32. Do YK, Eggleston KN. Educational disparities in quality of diabetes care in a universal health insurance system: evidence from the 2005 Korea National Health and Nutrition Examination Survey. Int J Qual Health Care 2011;23(4):397-404.

33. Cutler DM, Lleras-Muney A. Understanding differences in health behaviors by education. J Health Econ 2010;29(1):1-28.

34. Won MR, Choi YJ. Are Koreans prepared for the rapid increase of the single-household elderly? Life satisfaction and depression of the single-household elderly in Korea. ScientificWorldJournal 2013;2013:972194.

35. Crandall CJ, Merkin SS, Seeman TE, Greendale GA, Binkley N, Karlamangla AS. Socioeconomic status over the life-course and adult bone mineral density: the Midlife in the U.S. Study. Bone 2012;51(1):107-113.

36. Waugh EJ, Lam MA, Hawker GA, McGowan J, Papaioannou A, Cheung AM, et al. Risk factors for low bone mass in healthy 40-60 year old women: a systematic review of the literature. Osteoporos Int 2009;20(1):1-21. 